\title{
A public database for the new MLST scheme for Treponema pallidum subsp. pallidum: surveillance and epidemiology of the causative agent of syphilis
}

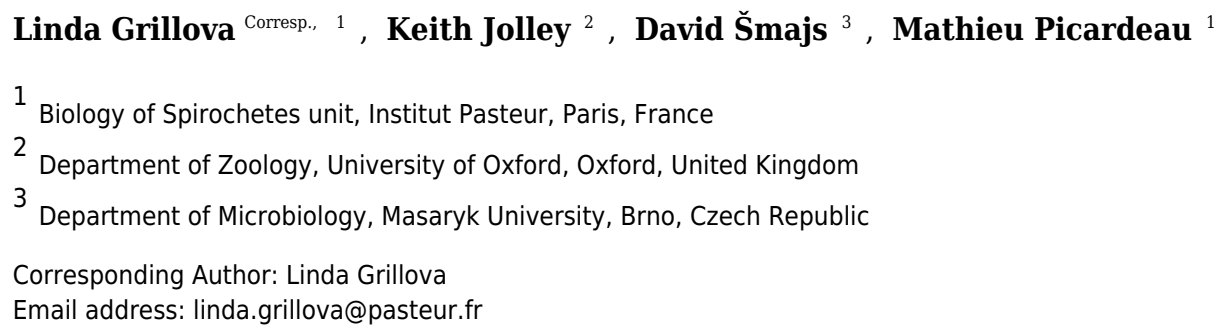

Treponema pallidum subsp. pallidum is the causative agent of syphilis, a sexually transmitted disease with worldwide prevalence. Several different molecular typing schemes are currently available for this pathogen. To enable population biology studies of the syphilis agent and for epidemiological surveillance at the global scale, a harmonized typing tool needs to be introduced. Recently, we published a new Multi-Locus Sequence Typing (MLST) with the potential to significantly enhance the epidemiological data in several aspects (e.g., distinguishing genetically different clades of syphilis, subtyping inside these clades, and, finally, distinguishing different subspecies of non-cultivable pathogenic treponemes). In this short report, we introduce the PubMLST database for treponemal DNA data storage and for assignments of allelic profiles and sequencing types. Moreover, we have summarized epidemiological data of all treponemal strains $(n=358)$ with available DNA sequences in typing loci and found several association between genetic groups and characteristics of patients. This study proposes the establishment of a single MLST of Treponema pallidum subsp. pallidum and encourages researchers and public health communities to use this PubMLST database as a universal tool for molecular typing studies of the syphilis pathogen. 


\section{A public database for the new MLST scheme for Treponema 2 pallidum subsp. pallidum: surveillance and epidemiology of 3 the causative agent of syphilis}

4

5 Linda Grillová ${ }^{2}$, Keith A. Jolley², David Šmajs ${ }^{3}$, Mathieu Picardeau ${ }^{1}$

6

$7 \quad{ }^{1}$ Biology of Spirochetes unit, Institut Pasteur, Paris, France

$8 \quad{ }^{2}$ Department of Zoology, University of Oxford, Oxford, UK

$9 \quad{ }^{3}$ Department of Biology, Masaryk University, Brno, Czech Republic

11 Corresponding Author:

12 Linda Grillová1

1328 Rue du Docteur Roux, Paris, 75024, France

14 Email address: lindagrillova@gmail.com 
15 ABSTRACT

16 Treponema pallidum subsp. pallidum is the causative agent of syphilis, a sexually transmitted 17 disease with worldwide prevalence. Several different molecular typing schemes are currently 18 available for this pathogen. To enable population biology studies of the syphilis agent and for epidemiological surveillance at the global scale, a harmonized typing tool needs to be introduced. Recently, we published a new Multi-Locus Sequence Typing (MLST) with the potential to significantly enhance the epidemiological data in several aspects (e.g., distinguishing genetically different clades of syphilis, subtyping inside these clades, and, finally, distinguishing different subspecies of non-cultivable pathogenic treponemes). In this short report, we introduce the PubMLST database for treponemal DNA data storage and for assignments of allelic profiles and sequencing types. Moreover, we have summarized epidemiological data of all treponemal strains $(n=358)$ with available DNA sequences in typing loci and found several association between genetic groups and characteristics of patients. This study proposes the establishment of a single MLST of Treponema pallidum subsp. pallidum and encourages researchers and public health communities to use this PubMLST database as a universal tool for molecular typing 30 studies of the syphilis pathogen. 


\section{INTRODUCTION}

Syphilis is a bacterial infection caused by Treponema pallidum subsp. pallidum (TPA). Despite the availability of effective treatments, the annual worldwide incidence recently reached more than 5.6 million cases (WHO, 2016).

The proper discrimination of strains of infectious pathogens is crucial for epidemiological and surveillance analyses, for description of population structure and dynamics and for the improvement of public health control strategies. More specifically, the association of specific strains of TPA with different groups of patients can result in a better understanding of syphilis epidemiology. Association of macrolide resistance/sensitivity and allelic profiles are particularly important for a better understanding of the emergence of antibiotic-resistant strains. Finally, the molecular typing of syphilis-causing strains can help to determine syphilis diagnosis, especially in cases with atypical symptoms, thereby preventing syphilis-bejel confusion (Grange et al., 2016; Noda et al., 2018).

Multi-Locus Sequence Typing (MLST) is typically based on amplification and sequencing of about seven housekeeping gene fragments (loci). For each locus, the different sequence variants are assigned as distinct alleles and, for each isolate, the combination of alleles defines the allelic profile and sequence type (ST). Allelic profiles and/or STs are used for definition of the strains and these can be clustered into clonal complexes based on shared alleles (Maiden et al., 2013). The traditional MLST approach is based on allele-based comparisons, where each allelic change is counted as a single event, regardless of the number of nucleotide changes involved. This helps to mitigate the effects of horizontal genetic transfer in organisms prone to recombination. The MLST data are commonly stored in publicly available and curated databases, such as PubMLST, which uses the Bacterial Isolate Genome Sequence Database (BIGSdb) platform (Jolley \& Maiden, 2010). These databases can be used to automatically identify and assign new allele variants and sequence types, and provide tools to analyze the origin and phenotypic metadata of samples with the genotypic information of the typed pathogens. Several functions are available within this software to analyze and visualize epidemiological data (Jolley \& Maiden, 2010; Maiden et al., 2013). BIGSdb is currently hosting over 100 different bacterial species and is one of the most widely used tools for epidemiological purposes (Jolley et al., 2018).

Recently, we published a new MLST scheme of TPA (Grillová et al, 2018a, Pospíśilová et al. 2018). The TPA MLST scheme is somewhat unusual compared to typical MLST schemes reflecting the special characteristics of TPA. The TPA MLST uses three highly variable loci and performs sequence-based analyses, i.e., it takes into account sequence differences among alleles.

i.) Even though some recent attempts to cultivate TPA were successful using TPA strains passed through cultures with rabbit epithelial cells (Edmondson et al, 2018), the in vitro cultivation of TPA strains isolated directly from patients is still not possible. It is, therefore, necessary to perform MLST directly from clinical samples, which usually contain a very low number of TPA DNA copies $\left(10-10^{2}\right.$ TPA DNA copies/ $\mu$ ) (Pinto et al., 2017). To ensure a high proportion of fully typed samples, the newly proposed MLST is based on three loci only, in comparison to the conventional seven-locus scheme used in other bacteria. 
ii.) MLST schemes are usually based on several housekeeping genes. However, this approach is not suitable for monomorphic bacteria as TPA (Smajs et al. 2012; Radolf et al. 2016; Šmajs et al. 2018). In this case, every single nucleotide variant (SNV) is important and valuable and the typing loci with the highest SNV density should be used to ensure sufficient variability to map the overall population diversity. However, the typing loci should still be stable over time. Therefore, the new MLST was designed on the principle of the sequence analyses using 3 highly variable loci - TP0136, TP0548 and TP0705 (Grillová et al, 2018a). These three loci represented the lowest number of loci with the highest discrimination power possible among the candidate loci selected for typing.

iii.) Because of the monomorphic character of TPA genome and the low number of typing loci, the "sequence-based analyses" approach is highly recommended. This approach, compared to the conventional "allele-based comparisons", allows the researcher to distinguish alleles based on a number of nucleotide differences and permits interpretation of the data using Maximum-likelihood phylogeny. Even though the TPA MLST uses only three typing loci, the scheme has a high resolution (more than $30 \%$ of the resolution achieved with genome-wide data). This approach also allows distinction of TPA from other treponemal subspecies and species, discriminates between the two TPA clades (TP0136, TP0548) (Nechvátal et al., 2014), and can be used for differentiation of strains within each of these clades (TP0136 for the Nichols clade, and TP0705 for the SS14 clade).

The purpose of this short report is to establish a single universal MLST scheme applicable to TPA (Grillová et al, 2018a) and introduce the PubMLST database for treponemal DNA data storage and ST assignments. 
97

98

99

100

101

102

103

104

105

106

107

108

109

110

111

112

113

114

115

116

117

118

119

120

121

122

123

124

125

126

127

128

129

130

131

132

133

134

135

136

\section{MATERIALS \& METHODS}

\section{Treponema pallidum subps. pallidum database hosted at PubMLST}

We have created a Treponema pallidum subsp. pallidum database hosted at PubMLST. PubMLST uses the BIGSdb platform for the storage and analysis of sequence data from bacterial isolates. The input format can be fasta files, which contain small contigs assembled from dideoxy chain termination sequencing of the typing loci, or complete or multiple contigs generated from next-generation sequencing platforms. When the new sequences are submitted to BIGSdb, the BLAST algorithm incorporated into BIGSdb identifies already known sequence variants or marks an unknown variant for curator verification. After verification by a curator, a novel allele number is assigned (Maiden et al., 2013). Metadata of the patients may be submitted to the database as well, and includes some important characteristics of isolates, e.g., isolate identification name/number; country where the strain was isolated; biological source of sample; year of isolation; and resistance to macrolide antibiotics. However, we encourage the researchers to upload as much information about patients and samples as available (e.g., age, sex and sexual orientation of the patients, stage of the disease, serological results etc.). The database can be accessed at https://pubmlst.org/tpallidum/. The database is primarily designed to be used as a tool for automatic ST assignments; for determination of new alleles; for storage of sample metadata; for identification of new associations between genetic types and metadata using various tools; and for user-friendly visualization of molecular typing data, particularly using GrapeTree (Zhou et al., 2018) and Microreact (Argimón et al., 2016) plugins. These plugins enable, for example, visualization of genomic epidemiology and phylogeography by showing the correlation of the STs and geographical areas in real time and visualization of phylogenetic data together with patient metadata.

However, this database can also serve as a repository for complete/draft genomes and genebased comparative genomic data (using the Genome comparator tool). Sequences and metadata can be exported from the database in multiple formats. The database is overseen by the curators, who will check the submitted data and who will be available for any additional help (see https://pubmlst.org/tpallidum/).

\section{Sequences submitted to PubMLST}

All published whole genome and draft genome sequences of TPA (Pětrošová et al, 2013; Giacani et al., 2010; Pětrošová et al., 2012; Zobaníková et al., 2012; Giacani et al., 2014; Tong et al., 2017; Arora et al., 2016; Sun et al., 2016; Pinto et al., 2016; Strouhal et al., 2018; Grillová et al. 2018b), data available at GenBank, as well as sequences obtained by MLST (Grillová et al, 2018a; Pospíšilová et al., 2018) were submitted to the database.

\section{Phylogenetic analyses}

The phylogenetic tree was generated using MEGA6 (Tamura et al., 2013) with the Maximum Likelihood bootstrap algorithm and Tamura Nei model based on concatenated sequences of typing loci of fully typed samples $(n=286)$. The tree was visualized using iTOL (Letunic \& Bork, 2016), available as an external plugin of the BIGSdb.

\section{Statistical analyses}


Statistical analyses were performed using STATISTICA software v.12 (StatSoft, Tulsa, 139 OK, USA) using data extracted from the Two-field breakdown option. A Fisher's exact test was 140 used to establish the correlations of patient's metadata and allelic variants and STs. Statistical 141 significance was set at $\mathrm{p}<0.05$. 


\section{RESULTS}

\section{Treponema pallidum subsp. pallidum database}

144

145

146

147

148

149

150

151

152

153

154

155

156

157

158

159

160

161

162

163

164

165

166

167

168

169

170

171

172

173

174

175

176

177

178

179

180

181

182

183
At the time of writing (September 2018), the databases contain 358 TPA strains, mostly isolated from Europe (70.87\%), followed by North America (26.33\%), Asia (2.52\%) and South America (0.28\%) (Table 1). More than $90 \%$ of samples were clinically acquired and 31 strains were propagated in rabbits. 71 samples represented whole/draft genomes and 287 samples were typed using MLST and yielded sequences only in typing loci. The samples were collected from 1912 to 2017. There were 272 samples collected from males (183 samples were collected from Men who have sex with men; MSM) and only four samples from females. Most of the samples were isolated from patients diagnosed with primary syphilis, followed by secondary syphilis, patients in the border of primary and secondary stage, and there were also 3 cases of congenital syphilis. The patients were between 0 and 71 years old. In addition, 21 samples were found negative by serology, but positive by PCR and all of them were isolated from patients with primary syphilis by genital, anal, or throat swab (Table 1). Most of the samples $(262,73.39 \%)$ contained treponemes resistant to macrolide antibiotics caused by A2058G mutations (in 257 cases) and A2059G mutations (in 5 cases) in both treponemal 23S rRNA genes.

Fully typed TPA strains ( $\mathrm{n}=285)$ were divided into 40 allelic profiles or strain types (ST1ST40), and further into two clonal complexes, where 31 STs belong to the clonal complex "SS14-like" and 9 STs to the clonal complex "Nichols-like" (Figure 1; Table 2). STs were divided based on the 137 variable sites in total present in the concatenated sequences of typing loci (2 $584 \mathrm{bp}$ ), where 46 variable positions were found to be parsimony informative for distinction of the two clonal complexes. The majority of the samples were found to belong to the SS14-like clonal complex (92.3\%), while only $7.7 \%$ of samples belonged to the Nichols-like clonal complex.

\section{Association found using TPA BIGSdb}

We have found several association between genetic data and metadata of the samples including patient characteristics. Nichols-like strains were found to be associated with susceptibility to macrolides, and, on the other hand, SS14-like strains were associated with the presence of mutations leading to macrolide resistance $(\mathrm{p}<0.0001)$ (Figure 2A). The data showed that Nichols-like strains appear to be spreading predominantly among MSM patients (Figure 2B). Moreover, Nichols-like strains were associated with an older population (35 years old and older, $p=0.0104$ ) (Figure 2C). Most of these association were already described previously (Grillová et al., 2014; Gallo Valuet et al., 2016; Read et al., 2016). However, in the future, there is a need to verify these association by examination of a higher number of treponemal strains from different geographical areas and from different groups of patients to avoid sampling biases.

ST1 was found to be the predominant sequencing type (allelic profile: 1.3.1, clonal complex: SS14-like). However, with the increasing number of newly submitted TPA strains, the number of different STs also increased, suggesting that the diversity of the TPA strains is still not fully revealed. Interestingly, five STs were found exclusively among the strains propagated in rabbits - ST20-ST24 $(n=8)$ and not among the strains isolated directly from patients. However, the remaining examined strains propagated in rabbits $(n=23)$ shared the same STs with the directly sequenced strains. 
184

185

186

187

188

189

190

191

192

193

194

195

196

197

198

199

200

201

202

203

204

205

206

207

208

209

210

211

212

213

214

215

216

217

218

219

220

\section{DISCUSSION}

Since TPA cannot be routinely cultivated in vitro, MLST needs to be performed directly from clinical samples. To obtain fully typed samples enabling assignment of ST, the amplification efficiency of all three loci needs to be as high as possible. The amplification efficiency depends on several factors, including the type of material taken from patients, the time between sampling and DNA isolation, the type of DNA isolation protocol as well as the type of amplification protocol.

As reported in many studies, the highest concentration of the treponemal DNA is present in swabs taken from the primary chancre, followed by blood-derived samples, cerebrospinal fluid and others (Peng et al., 2011; Pinto et al., 2017). E.g., the swabs taken from primary chancre represent the samples with the highest concentration of treponemal DNA and are the most suitable candidates for MLST. However, MLST profiles revealed from parallel samples taken from the same patient (e.g., primary chancer swab and whole blood) are also important with respect to the stability of the used typing loci. For instance, the typing loci used in the enhanced CDC-typing (based on restriction fragment length polymorphism analyses of the tprEGJ genes and a number of repeats in the arp gene (Marra et al., 2010) were identified to be genetically unstable (Mikalová et al., 2013). This genetic instability was shown by revealing the different subtypes in samples isolated from swab and whole blood, both taken from the same patient. Loci selected for MLST (TP0136, TP0548 and TP0705) are considered to be genetically stable, showing the same allelic profiles in parallel samples as well as in samples collected from different rabbit passages (Grillová et al, 2018a).

Another important factor to obtain high-quality DNA is the time between sampling of patients and the DNA isolation. This time period should be as short as possible. If immediate DNA isolation is not possible, the swab extracts (PBS) should be stored at $-20{ }^{\circ} \mathrm{C}$. The swab extracts should be centrifuged at the lowest possible speed for 10 minutes and the supernatant should be used for the subsequent isolation of DNA. Even though it is time consuming, nested PCR should be used for target loci amplification to achieve the highest amplification efficiency. Moreover, we recommend looking for the presence or absence of A2058G and A2059G mutations in 23S rDNA, which encodes the macrolide resistance (Grillová et al, 2018a).

Most of TPA strains analyzed to date from experimentally infected rabbits belong to the Nichols-like group, while most clinical TPA isolates obtained directly from patients belong to the SS14-like group (Šmajs et al., 2016). We encourage researchers and public health communities to use MLST, which is able to distinguish these two clonal complexes. Moreover, we recommend submitting the sequencing data to PubMLST along with the metadata (including data from the serological tests). The expansion of the sample set in the PubMLST with syphilis isolates from different geographical areas can lead to a better understanding of the epidemiology of the two genetically distinct groups of syphilis treponemes. 


\section{CONCLUSIONS}

222

223

224

225

226

227

228

229

230

\section{ACKNOWLEDGEMENT}

232 We thank to Dr. Robert Anthony Gaultney for English editing. 
233

234

235

236

237

238

239

240

241

242

243

244

245

246

247

248

249

250

251

252

253

254

255

256

257

258

259

260

261

262

263

264

265

266

267

268

269

270

271

272

273

274

275

276

277

278

\section{REFERENCES}

Argimón, S., Abudahab, K., Goater, R.J.E., Fedosejev, A., Bhai, J., Glasner, C., Feil, E.J., Holden, M.T.G., Yeats, C.A., Grundmann, H., Spratt, B.G., Aanensen, D.M., 2016. Microreact: visualizing and sharing data for genomic epidemiology and phylogeography. Microb Genom 2, e000093. https://doi.org/10.1099/mgen.0.000093

Arora, N., Schuenemann, V.J., Jäger, G., Peltzer, A., Seitz, A., Herbig, A., Strouhal, M., Grillová, L., Sánchez-Busó, L., Kühnert, D., Bos, K.I., Davis, L.R., Mikalová, L., Bruisten, S., Komericki, P., French, P., Grant, P.R., Pando, M.A., Vaulet, L.G., Fermepin, M.R., Martinez, A., Centurion Lara, A., Giacani, L., Norris, S.J., Šmajs, D., Bosshard, P.P., González-Candelas, F., Nieselt, K., Krause, J., Bagheri, H.C., 2016. Origin of modern syphilis and emergence of a pandemic Treponema pallidum cluster. Nat Microbiol 2, 16245. https://doi.org/10.1038/nmicrobiol.2016.245

Edmondson, D.G., Hu, B., Norris, S.J., 2018. Long-Term In Vitro Culture of the Syphilis Spirochete Treponema pallidum subsp. pallidum. MBio 9. https://doi.org/10.1128/mBio.01153-18

Gallo Vaulet, L., Grillová, L., Mikalová, L., Casco, R., Rodríguez Fermepin, M., Pando, M.A., Šmajs, D., 2017. Molecular typing of Treponema pallidum isolates from Buenos Aires, Argentina: Frequent Nichols-like isolates and low levels of macrolide resistance. PLoS ONE 12, e0172905. https://doi.org/10.1371/journal.pone.0172905

Giacani, L., Iverson-Cabral, S.L., King, J.C.K., Molini, B.J., Lukehart, S.A., Centurion-Lara, A., 2014. Complete Genome Sequence of the Treponema pallidum subsp. pallidum Sea81-4 Strain. Genome Announc 2. https://doi.org/10.1128/genomeA.00333-14

Giacani, L., Jeffrey, B.M., Molini, B.J., Le, H.T., Lukehart, S.A., Centurion-Lara, A., Rockey, D.D., 2010. Complete genome sequence and annotation of the Treponema pallidum subsp. pallidum Chicago strain. J. Bacteriol. 192, 2645-2646. https://doi.org/10.1128/JB.00159-10

Grange, P.A., Mikalová, L., Gaudin, C., Strouhal, M., Janier, M., Benhaddou, N., Šmajs, D., Dupin, N., 2016. Treponema pallidum 11qj Subtype May Correspond to a Treponema pallidum Subsp. Endemicum Strain. Sex Transm Dis 43, 517-518. https://doi.org/10.1097/OLQ.0000000000000474

Grillová, L., Bawa, T., Mikalová, L., Gayet-Ageron, A., Nieselt, K., Strouhal, M., Sednaoui, P., Ferry, T., Cavassini, M., Lautenschlager, S., Dutly, F., Pla-Díaz, M., Krützen, M., González-Candelas, F., Bagheri, H.C., Šmajs, D., Arora, N., Bosshard, P.P., 2018. Molecular characterization of Treponema pallidum subsp. pallidum in Switzerland and France with a new multilocus sequence typing scheme. PLoS ONE 13, e0200773. https://doi.org/10.1371/journal.pone.0200773.

Grillová L, Giacani L, Mikalová L, Strouhal M, Strnadel R, Marra C, Centurion-Lara A, Poveda L, Russo G, Čejková D, Vašků V, Oppelt J, Šmajs D., 2018. Sequencing of Treponema pallidum subsp. pallidum from isolate UZ1974 using Anti-Treponemal Antibodies Enrichment: First complete whole genome sequence obtained directly from human clinical material. PLoS ONE 3(8), e0202619. doi: 10.1371/journal.pone.0202619.

Grillová L, Pětrošová, H., Mikalová, L.,Strnadel et al. 2014. Molecular typing of Treponema pallidum subsp. pallidum in the Czech Republic during 2011 to 2013: Increased prevalence of identified genotypes and of isolates with macrolide resistance. J Clin Microbiol. 52(10):3693-37000.

Jolley, K.A., Maiden, M.C.J., 2010. BIGSdb: Scalable analysis of bacterial genome variation at 
the population level. BMC Bioinformatics 11, 595. https://doi.org/10.1186/1471-2105$11-595$

Letunic, I., Bork, P., 2016. Interactive tree of life (iTOL) v3: an online tool for the display and annotation of phylogenetic and other trees. Nucleic Acids Res. 44, W242-245. https://doi.org/10.1093/nar/gkw290

Maiden, M.C.J., Jansen van Rensburg, M.J., Bray, J.E., Earle, S.G., Ford, S.A., Jolley, K.A., McCarthy, N.D., 2013. MLST revisited: the gene-by-gene approach to bacterial genomics. Nat. Rev. Microbiol. 11, 728-736. https://doi.org/10.1038/nrmicro3093

Marra, C.M., Sahi, S.K., Tantalo, L.C., Godornes, C., Reid, T., Behets, F., Rompalo, A., Klausner, J.D., Yin, Y.P., Mulcahy, F., Golden, M.R., Centurion-Lara, A., Lukehart, S.A., 2010. Enhanced molecular typing of treponema pallidum: geographical distribution of strain types and association with neurosyphilis. J. Infect. Dis. 202, 1380-1388. https://doi.org/10.1086/656533

Mikalová, L., Pospíšilová, P., Woznicová, V., Kuklová, I., Zákoucká, H., Šmajs, D., 2013. Comparison of CDC and sequence-based molecular typing of syphilis treponemes: tpr and arp loci are variable in multiple samples from the same patient. BMC Microbiol. 13, 178. https://doi.org/10.1186/1471-2180-13-178

Nechvátal, L., Pětrošová, H., Grillová, L., Pospíšilová, P., Mikalová, L., Strnadel, R., Kuklová, I., Kojanová, M., Kreidlová, M., Vaňousová, D., Procházka, P., Zákoucká, H., Krchňáková, A., Šmajs, D., 2014. Syphilis-causing strains belong to separate SS14-like or Nichols-like groups as defined by multilocus analysis of 19 Treponema pallidum strains. Int. J. Med. Microbiol. 304, 645-653. https://doi.org/10.1016/j.ijmm.2014.04.007

Noda, A.A., Grillová, L., Lienhard, R., Blanco, O., Rodríguez, I., Šmajs, D., 2018. Bejel in Cuba: molecular identification of Treponema pallidum subsp. endemicum in patients diagnosed with venereal syphilis. Clin. Microbiol. Infect. https://doi.org/10.1016/j.cmi.2018.02.006

Peng, R.-R., Wang, A.L., Li, J., Tucker, J.D., Yin, Y.-P., Chen, X.-S., 2011. Molecular typing of Treponema pallidum: a systematic review and meta-analysis. PLoS Negl Trop Dis 5, e1273. https://doi.org/10.1371/journal.pntd.0001273

Pětrošová, H., Pospíšilová, P., Strouhal, M., Čejková, D., Zobaníková, M., Mikalová, L., Sodergren, E., Weinstock, G.M., Šmajs, D., 2013. Resequencing of Treponema pallidum ssp. pallidum strains Nichols and SS14: correction of sequencing errors resulted in increased separation of syphilis treponeme subclusters. PLoS ONE 8, e74319. https://doi.org/10.1371/journal.pone.0074319

Pětrošová, H., Zobaníková, M., Čejková, D., Mikalová, L., Pospíšilová, P., Strouhal, M., Chen, L., Qin, X., Muzny, D.M., Weinstock, G.M., Šmajs, D., 2012. Whole genome sequence of Treponema pallidum ssp. pallidum, strain Mexico A, suggests recombination between yaws and syphilis strains. PLoS Negl Trop Dis 6, e1832. https://doi.org/10.1371/journal.pntd.0001832

Pinto, M., Antelo, M., Ferreira, R., Azevedo, J., Santo, I., Borrego, M.J., Gomes, J.P., 2017. A retrospective cross-sectional quantitative molecular approach in biological samples from patients with syphilis. Microb. Pathog. 104, 296-302. https://doi.org/10.1016/j.micpath.2017.01.059

Pinto, M., Borges, V., Antelo, M., Pinheiro, M., Nunes, A., Azevedo, J., Borrego, M.J., Mendonça, J., Carpinteiro, D., Vieira, L., Gomes, J.P., 2016. Genome-scale analysis of the non-cultivable Treponema pallidum reveals extensive within-patient genetic 
variation. Nat Microbiol 2, 16190. https://doi.org/10.1038/nmicrobiol.2016.190

Pospíšilová, P., Grange, P.A., Grillová, L., Mikalová, L., Martinet, P., Janier, M., Vermersch, A., Benhaddou, N., Del Giudice, P., Alcaraz, I., Truchetet, F., Dupin, N., Šmajs, D., 2018. Multi-locus sequence typing of Treponema pallidum subsp. pallidum present in clinical samples from France: Infecting treponemes are genetically diverse and belong to 18 allelic profiles. PLoS ONE 13, e0201068. https://doi.org/10.1371/journal.pone.0201068

Radolf, J.D., Deka, R.K., Anand, A., Šmajs, D., Norgard, M.V., Yang, X.F., 2016. Treponema pallidum, the syphilis spirochete: making a living as a stealth pathogen. Nat. Rev. Microbiol. 14, 744-759. https://doi.org/10.1038/nrmicro.2016.141

Read, P., Tagg, K.A., Jeoffreys, N., Guy, R.J., Gilbert, G.L., Donovan, B., 2016. Treponema pallidum Strain Types and Association with Macrolide Resistance in Sydney, Australia: New TP0548 Gene Types Identified. J. Clin. Microbiol. 54, 2172-2174. https://doi.org/10.1128/JCM.00959-16

Šmajs, D., Mikalova, L., Strouhal, M., Grillova, L., 2016. Why Are There Two Genetically Distinct Syphilis-Causing Strains? FIDT 7. https://doi.org/10.1615/ForumImmunDisTher.2017020184

Šmajs, D., Norris, S.J., Weinstock, G.M., 2012. Genetic diversity in Treponema pallidum: implications for pathogenesis, evolution and molecular diagnostics of syphilis and yaws. Infect. Genet. Evol. 12, 191-202. https://doi.org/10.1016/j.meegid.2011.12.001

Šmajs, D., Strouhal, M., Knauf, S., 2018. Genetics of human and animal uncultivable treponemal pathogens. Infect. Genet. Evol. 61, 92-107. https://doi.org/10.1016/j.meegid.2018.03.015

Strouhal, M., Oppelt, J., Mikalová, L., Arora, N., Nieselt, K., González-Candelas, F., Šmajs, D., 2018. Reanalysis of Chinese Treponema pallidum samples: all Chinese samples cluster with SS14-like group of syphilis-causing treponemes. BMC Res Notes 11, 16. https://doi.org/10.1186/s13104-017-3106-7

Sun, J., Meng, Z., Wu, K., Liu, B., Zhang, S., Liu, Y., Wang, Y., Zheng, H., Huang, J., Zhou, P., 2016. Tracing the origin of Treponema pallidum in China using next-generation sequencing. Oncotarget 7, 42904-42918. https://doi.org/10.18632/oncotarget.10154

Tamura, K., Stecher, G., Peterson, D., Filipski, A., Kumar, S., 2013. MEGA6: Molecular Evolutionary Genetics Analysis version 6.0. Mol. Biol. Evol. 30, 2725-2729. https://doi.org/10.1093/molbev/mst197

Tong, M.-L., Zhao, Q., Liu, L.-L., Zhu, X.-Z., Gao, K., Zhang, H.-L., Lin, L.-R., Niu, J.-J., Ji, Z.-L., Yang, T.-C., 2017. Whole genome sequence of the Treponema pallidum subsp. pallidum strain Amoy: An Asian isolate highly similar to SS14. PLoS ONE 12, e0182768. https://doi.org/10.1371/journal.pone.0182768

Jolley KA, Bray JE and Maiden MCJ. Open-access bacterial population genomics: BIGSdb software, the PubMLST.org website and their applications [version 1; referees: awaiting peer review]. Wellcome Open Res 2018, 3:124. doi: 10.12688/wellcomeopenres.14826.1.

World Health Organization. WHO guidelines for the treatment of Treponema pallidum (syphilis). 2016; Available at: http://www.who.int/reproductivehealth/publications/rtis/syphilis-treatmentguidelines/en/.

Zhou, Z., Alikhan, N.-F., Sergeant, M.J., Luhmann, N., Vaz, C., Francisco, A.P., Carriço, J.A., Achtman, M., 2018. GrapeTree: visualization of core genomic relationships among 100,000 bacterial pathogens. Genome Res. 28, 1395-1404. https://doi.org/10.1101/gr.232397.117 
371 Zobaníková, M., Mikolka, P., Cejková, D., Pospíšilová, P., Chen, L., Strouhal, M., Qin, X., 372 Weinstock, G.M., Śmajs, D., 2012. Complete genome sequence of Treponema pallidum 373 strain DAL-1. Stand Genomic Sci 7, 12-21. https://doi.org/10.4056/sigs.2615838 
Table $\mathbf{1}$ (on next page)

Clinical characteristics of the TPA strains submitted to the BIGSdb 
1

2 Table 1: Clinical characteristics of the TPA strains submitted to the BIGSdb

3

\begin{tabular}{|c|c|c|c|c|c|}
\hline \multicolumn{2}{|l|}{ Continent (n, \%) } & \multicolumn{2}{|c|}{ Clinical source $(n, \%)$} & \multicolumn{2}{|l|}{ Stage $(n, \%)$} \\
\hline Europe & $253(70.87)$ & Genital swab & $180(50.42)$ & Primary & $119(33.33)$ \\
\hline Norh America & $94(26.33)$ & Anal swab & $56(15.69)$ & Primary/Secondary & $8(2.24)$ \\
\hline Asia & $9(2.52)$ & Throat swab & $39(10.92)$ & Secondary & $40(11.2)$ \\
\hline South America & $1(0.28)$ & Skin lesion & $17(4.76)$ & Congenital & $3(0.84)$ \\
\hline \multicolumn{2}{|l|}{ Country $(n, \%)$} & Blood & $3(0.84)$ & Unspecified & $187(52.38)$ \\
\hline France & $146(40.90)$ & CSF & $2(0.56)$ & \multicolumn{2}{|c|}{ Macrolide resistance (n, \%) } \\
\hline Cuba & $72(20.17)$ & Amniotic fluid & $1(0.28)$ & Resistant & $262(73.39)$ \\
\hline Switzerland & $72(20.17)$ & Tissue & $1(0.28)$ & Sensitive & $62(18.3)$ \\
\hline Portugal & $25(7)$ & Other & $1(0.28)$ & Not done & $33(9.24)$ \\
\hline USA & $21(5.88)$ & Unspecified & $57(15.97)$ & \multicolumn{2}{|l|}{ Mutations (n, \%) } \\
\hline China & $9(2.52)$ & \multicolumn{2}{|l|}{$\operatorname{Sex}(n, \%)$} & \multirow{3}{*}{$\begin{array}{l}\text { A2058G } \\
\text { A2059G } \\
\text { Unspecified }\end{array}$} & \multirow{3}{*}{$\begin{array}{l}257(71.99) \\
5(1.4) \\
95(26.61)\end{array}$} \\
\hline Netherlands & $5(1.4)$ & \multirow{3}{*}{$\begin{array}{l}\text { Male } \\
\text { Female } \\
\text { Unspecified }\end{array}$} & $272(76.19)$ & & \\
\hline Austria & $3(0.84)$ & & $8(2.24)$ & & \\
\hline Czech Republic & $2(0.56)$ & & $77(21.5)$ & \multicolumn{2}{|l|}{ Serology $(n, \%)$} \\
\hline Argentina & $1(0.280$ & \multicolumn{2}{|c|}{ Sexual orientation $(\mathrm{n}, \%)$} & \multirow{5}{*}{$\begin{array}{l}\text { Positive } \\
\text { Negative } \\
\text { Unspecified }\end{array}$} & \multirow{5}{*}{$\begin{array}{l}182(50.98) \\
21(5.88) \\
154(43.14)\end{array}$} \\
\hline Mexico & $1(0.28)$ & \multirow{4}{*}{$\begin{array}{l}\text { MSM } \\
\text { MSW } \\
\text { WSM } \\
\text { Unspecified }\end{array}$} & $183(51.26)$ & & \\
\hline Source $(n, \%)$ & & & $27(7.56)$ & & \\
\hline Clinically acquired & $326(91.32)$ & & $3(0.84)$ & & \\
\hline Experimental animals & $31(8.68)$ & & $144(40.34)$ & & \\
\hline
\end{tabular}

4 CSF - cerebrospinal fluid.

5 MSM - Men who have sex with men.

6 MSW - Men who have sex with woman.

7 WSM - Woman who have sex with men. 


\section{Table 2 (on next page)}

Sequencing types found among 286 TPA fully typed strains submitted to the BIGSdb 
1 Table 2: Sequencing types found among 286 TPA fully typed strains submitted to the 2 BIGSdb.

\begin{tabular}{llllll}
\hline ST & TP0136 & TP0548 & TP0705 & Clonal complex & No. of samples \\
\hline 1 & 1 & 3 & 1 & SS14-like & 169 \\
2 & 1 & 1 & 1 & SS14-like & 37 \\
3 & 1 & 1 & 8 & SS14-like & 13 \\
4 & 7 & 1 & 9 & SS14-like & 5 \\
5 & 2 & 1 & 2 & SS14-like & 3 \\
6 & 3 & 2 & 3 & Nichols-like & 3 \\
7 & 1 & 4 & 1 & SS14-like & 3 \\
8 & 1 & 5 & 1 & SS14-like & 2 \\
9 & 4 & 3 & 1 & SS14-like & 1 \\
10 & 1 & 11 & 8 & SS14-like & 3 \\
11 & 1 & 1 & 3 & SS14-like & 4 \\
12 & 5 & 3 & 8 & SS14-like & 1 \\
13 & 6 & 3 & 1 & SS14-like & 1 \\
14 & 1 & 8 & 1 & SS14-like & 1 \\
15 & 1 & 3 & 5 & SS14-like & 1 \\
16 & 1 & 3 & 7 & SS14-like & 1 \\
17 & 13 & 1 & 1 & SS14-like & 1 \\
18 & 1 & 9 & 1 & SS14-like & 1 \\
19 & 1 & 1 & 10 & SS14-like & 2 \\
20 & 10 & 14 & 10 & Nichols-like & 3 \\
21 & 1 & 13 & 10 & SS14-like & 1 \\
22 & 11 & 14 & 10 & Nichols-like & 2 \\
23 & 12 & 15 & 10 & Nichols-like & 1 \\
24 & 6 & 1 & 8 & SS14-like & 1 \\
25 & 1 & 26 & 1 & SS14-like & 1 \\
26 & 9 & 7 & 3 & Nichols-like & 6 \\
27 & 1 & 1 & 9 & SS14-like & 2 \\
28 & 1 & 17 & 9 & SS14-like & 2 \\
29 & 1 & 18 & 1 & SS14-like & 1 \\
30 & 1 & 19 & 1 & SS14-like & 1 \\
31 & 9 & 20 & 3 & Nichols-like & 1 \\
32 & 14 & 3 & 1 & SS14-like & 1 \\
33 & 1 & 1 & 11 & SS14-like & 1 \\
34 & 1 & 22 & 12 & SS14-like & 1 \\
35 & 1 & 23 & 1 & SS14-like & 1 \\
36 & 1 & 1 & 13 & SS14-like & 1 \\
37 & 15 & 7 & 3 & Nichols-like & 4 \\
& & & & &
\end{tabular}




\begin{tabular}{lllllll}
3 & 38 & 9 & 24 & 8 & Nichols-like & 1 \\
& 39 & 9 & 25 & 3 & Nichols-like & 1 \\
4 & 40 & 16 & 3 & 1 & SS14-like & 1 \\
\hline
\end{tabular}




\section{Figure 1}

Phylogeny of all fully typed samples $(n=286)$ divided into 40 STs and two clonal complexes (Nichols-like and SS14-like), based on concatenated sequences of typing loci.

Blue color represents the SS14-like clade and red color represents the Nichols-like clade. The green squares mark the macrolide sensitive strains and the orange squares mark the resistant strains. 


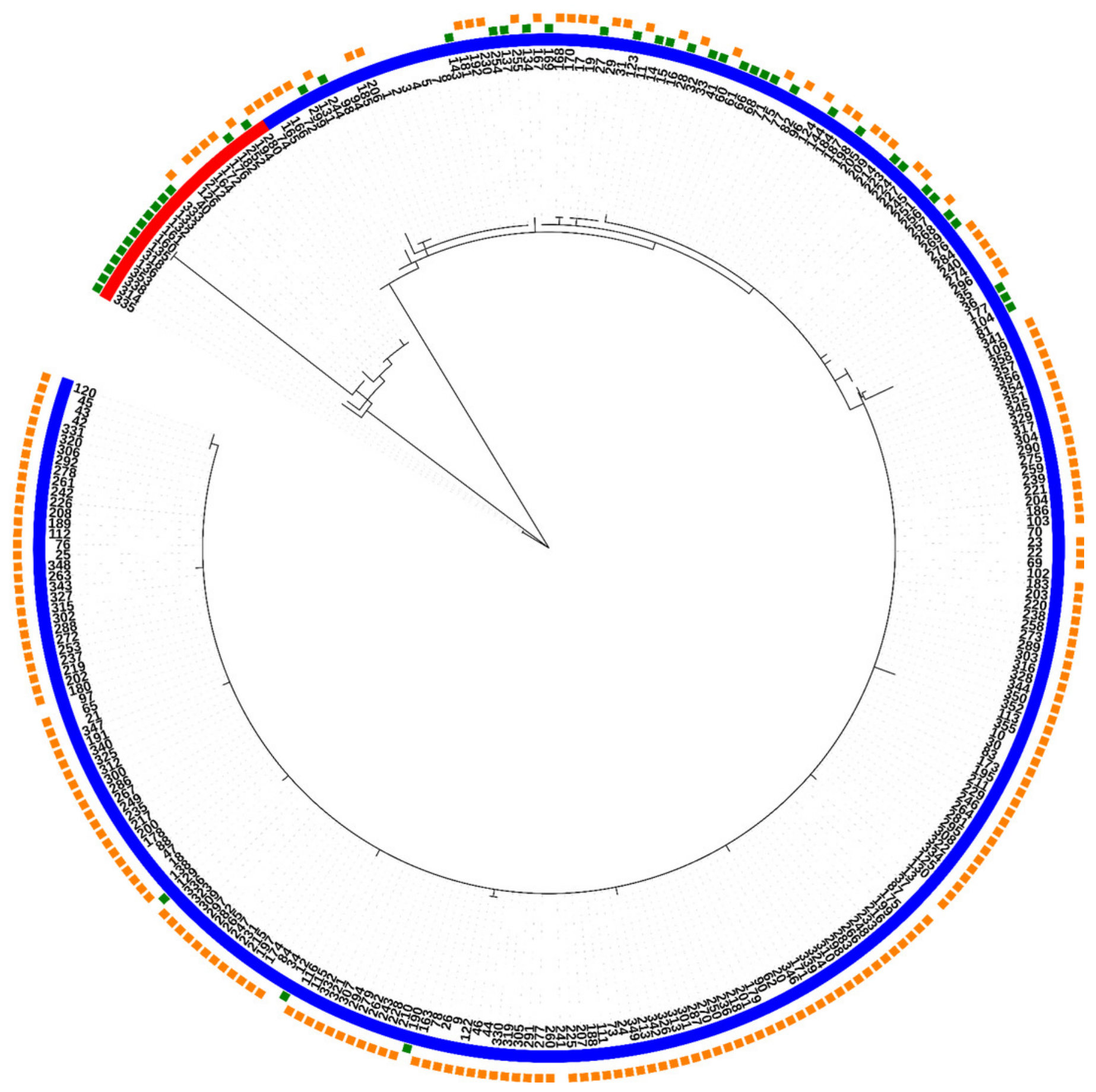




\section{Figure 2}

Clonal complexes associated with the macrolide sensitivity/resistance (A.); sexual orientation (B); and age of the patients (C).

The figure was created based on the BIGSdb output.

SS14 - like

Nichols - like

Clonal complex not determined

A.) Macrolide sensitivity/resistance

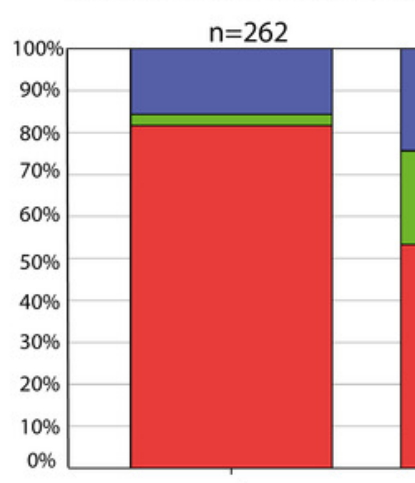

$8 e^{3 s^{3 x^{x}}}$ $n=62$

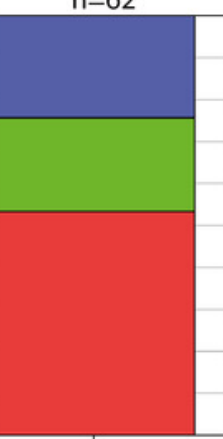

$e^{e^{3 e^{2}}}$

\section{Clonal complexes}

vs.

B.) Sexual orientation

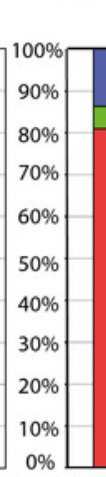

$\mathrm{n}=158$

$\mathrm{n}=21$

$n=3$

C.) Age

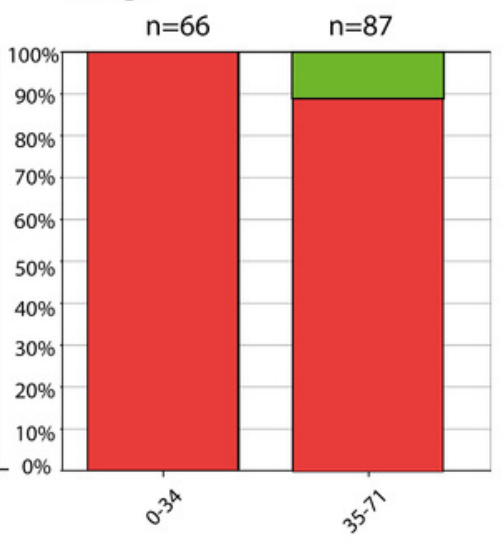

